\title{
LA GESTIÓN DE LA INTERCULTURALIDAD EN TIEMPOS DE CRISIS: EL DISCURSO DE LOS TÉCNICOS MUNICIPALES EN CATALUÑA
}

\section{THE MANAGEMENT OF INTERCULTURALITY \\ IN TIMES OF CRISIS: THE DISCOURSE OF TECHNICIANS IN LOCAL ADMINISTRATION IN CATALONIA}

XiAna Bueno* y Andreu Domingo**

Resumen: Este texto analiza el discurso de los técnicos municipales de inmigración sobre el impacto que la crisis económica y las políticas de ajuste han tenido tanto en la transformación de la demanda como en la gestión de la misma en un contexto -el de Cataluña-marcado por haber adoptado la interculturalidad como discurso normativo. Para tal fin nos servimos de las entrevistas realizadas a 20 técnicos de inmigración y 10 cargos políticos responsables del área de inmigración de sus respectivos municipios seleccionados a partir de una tipología previa sobre la existencia o no de enclaves residenciales, el nivel de segregación y el tamaño del municipio. Sus discursos nos permiten dibujar el entramado de relaciones que los mismos gestores perciben entre su propio trabajo y la población inmigrada, en medio de la recesión y bajo el influjo de un discurso político también cambiante.

Department of Sociology - Harvard University. xianabuenogarcia@fas.harvard.edu

** Centre d'Estudis Demogràfics (CED) - Universitat Autònoma de Barcelona. adomingo@ced.uab.es 
Palabras clave: población inmigrada, gestión local, interculturalidad, crisis económica, Cataluña.

Abstract: This work analyzes the discourse of front-desk immigration policy makers at the local level on the impact of the economic crisis and the denominated "adjustment policies» on the changes in migrant's demand and management of the same policies. This happens in a specific context -the Catalan one- which has adopted an Interculturality discourse as a normative discourse. To do this, we analyzed a set of personal interviews with 20 frontdesk local policy makers in the immigration area and 10 politicians also responsible for immigration issues within their municipalities. Municipalities were selected according to a previous typology based on the presence or not of residential enclaves, the segregation level and the population size. Interviewee's discourse allow us to outline the complexity of relationships that the policy manager's perceive between their own work and the migrant population, in a context of economic recession and under the influx of a changing political discourse.

Keywords: migrant population, local management, interculturality, economic crisis, Catalonia.

\section{INTRODUCCIÓN: ¿CRISIS O CAMBIO DE MODELO?}

Justo al inicio de la crisis económica, en Cataluña, como en el resto de España, los programas de acogida estaban centrando la mayoría de las acciones emprendidas por las diferentes áreas de atención a la inmigración. No era de extrañar, en 2007 se alcanzaba el máximo de entradas de flujos migratorios (más de 950 mil entradas), así como el máximo de solicitudes de reagrupación familiar concedidas y efectuadas (más de 33 mil), tras la última operación de regularización, conocida como Normalización de 2005 (Domingo, et al., 2010). Con las elecciones municipales de mayo de 2007, el debate sobre la gestión local de la inmigración había saltado a primer plano en Cataluña (volvería con más crudeza en 2010, a partir de las declaraciones del alcalde de Vic, negándose a empadronar a las personas en situación irregular), y aunque la pretensión de utilizar el Padrón municipal de habitantes con fines selectivos viniera de lejos, no había sido hasta 2008 que las crecientes 
trabas y restricciones al empadronamiento en algunos municipios habían provocado las protestas de diferentes ONG, lo suficiente como para llamar la atención del Síndic de Greuges (Sánchez, et al., 2008; Domingo y Sabater, 2010). Fruto de esa preocupación, así como continuación de un diseño político que había definido la interculturalidad como un modelo de política propia en Cataluña, y que había encontrado además en la política de integración de la inmigración una forma de afirmación del autogobierno (Gil Araujo, 2008; Zapata-Barrero, 2012), había sido el flamante Pacte nacional per la immigració promovido por la Secretaria General per la Immigració de la Generalitat de Catalunya, y firmado en diciembre de 2008 (Generalitat de Cataluña, 2009). Y entonces, llegó la crisis. O mejor dicho, llegó plenamente la conciencia de crisis económica.

A finales del año 2011, la crisis económica por supuesto, más grave que una simple alternancia de ciclo, de una profundidad por entonces desconocida, se imponía como una realidad absoluta. La llamada política de austeridad (Gil Calvo, 2009), impulsada por el cambio de gobierno autonómico en 2010 y el del central en 2011, repetía como un mantra que había llegado la hora de apretarse el cinturón, y que se había abusado de unos medios limitados. Lo que servía para los individuos, se aplicaba también a la propia administración. Como otras crisis anteriores, esta parecía haber dejado en evidencia la incapacidad de las ciencias sociales para anticipar lo que ha de venir de la que muchos presumen y, lo que es peor, ponía al descubierto la torpeza para ofrecer una respuesta, atrapada como todo lo demás -individuos, instituciones y saberes-, en la perplejidad. También la propia administración.

Con la más que evidente caída de los flujos migratorios añadida a la creciente escasez de medios económicos, se decidió que las políticas locales destinadas a la migración: las políticas centradas en el asentamiento de la población inmigrada, habían dejado de ser una prioridad. Es así como los fondos destinados a la integración de la población, creados en 2004 con un presupuesto de 7 millones de euros y que alcanzó los 200 millones en 2009, fueron suprimidos por completo en 2012 (Montilla y Rodríguez, 2014). Dentro del discurso general, se enfrentó ese recorte como un reto; en el discurso oficial como "una oportunidad para lograr una mayor eficiencia en la gestión». Había llegado el momento de replantearse el diseño de las políticas migratorias a nivel local. Si acorde con el crecimiento de los flujos migratorios, y por tanto 
de la población resultante de origen extranjero, se reconocía progresivamente el protagonismo de la administración local en esa gestión, la recentralización, es decir, el recorte de la autonomía de la administración municipal, no podía por menos que empezar con las competencias en materia de política de la población inmigrada. Eso sucedía en toda España, pero en Cataluña de alguna manera se había anticipado, constituyendo además una discusión más enconada si cabe, debido a la importancia que habían adquirido las políticas dirigidas a la población inmigrada en la propia definición de una política local diferenciada de la del gobierno central. La sospecha y la duda que iba en aumento era si nos encontrábamos únicamente ante la adaptación a la mengua de recursos humanos y materiales producida por la crisis económica, o si se aprovechaba también esta para propiciar la imposición de un nuevo modelo, que no parecía tampoco estar definido. Por entonces, era indudable que el gobierno central aprovechaba la crisis para llevar a cabo una operación de recentralización, absorbiendo competencias de la administración municipal, a la que se acusaba de falta de previsión en el mejor de los casos, y de despilfarro, arrastrada por el maremoto de la especulación inmobiliaria en el peor. En concreto los municipios dejan de ser emisores de los informes de extranjería y las autorizaciones de trabajo pasan a ser competencia autonómica. El Proyecto de la Ley de racionalización y sostenibilidad de la Administración Local (que se presentaba en el Congreso de los Diputados a inicios de agosto de 2013 y entraba en vigor el 31 de diciembre del mismo año, Ley 27/2013, BOE n. 312), pronto vendría a ratificar esas sospechas. También en el área concreta de las migraciones se verificaba esa corriente centralizadora en una de las materias claves de su gestión, los servicios sociales, que son líderes de las políticas de gestión de la inmigración en algunos municipios especialmente a raíz de la recesión económica. Pero había algo más, y ese algo más, escapaba a la dinámica y a las tensiones que habían caracterizado la demanda de competencias en materia de migraciones entre el gobierno central y el autonómico.

¿Asistíamos a un cambio de modelo? La incertidumbre era palpable a primera línea, entre los técnicos municipales de inmigración. Incertidumbre sobre la reorganización de servicios e incluso sobre la propia continuidad. El propósito de este trabajo es pues el de conocer cómo los gestores locales de la inmigración han percibido los cambios acontecidos hasta el momento y cuáles son 
sus expectativas relativas al futuro de la gestión, para así, a través de sus discursos identificar las claves que pueden estar ejemplificando un cambio de modelo en la administración local en relación al discurso hegemónico intercultural en Cataluña.

La literatura científica se ha centrado en numerosas ocasiones en el discurso político y el mediático sobre la inmigración, sin embargo mucha menor atención se la ha prestado al de los gestores a nivel técnico. No obstante, no es esta la primera vez que el discurso institucional sobre la gestión de la inmigración es objeto del interés científico. Existen en la literatura previa algunos ejemplos, aunque escasos, de trabajos que a nivel local o infra-local han abordado la gestión de la inmigración. Se ha destacado el papel multifuncional de los técnicos locales como agentes de la mediación intercultural tanto en la interlocución con la población autóctona, como en la aproximación a la población inmigrada (Dominguez y Brey, 2010). En el contexto de Cataluña, Dueñas (2011) aborda el papel institucional que los técnicos representan en el fomento de la participación entre los jóvenes de origen inmigrado.

\section{FUENTES Y METODOLOGÍA}

Si bien el presente trabajo tiene un enfoque eminentemente cualitativo, en su diseño reside una aproximación metodológica mixta ya que a raíz de un análisis cuantitativo de la distribución territorial de la población inmigrada se han seleccionado las entidades locales en las que realizar el análisis cualitativo. La aproximación cualitativa se ha hecho mediante entrevistas en profundidad de tipo semi-estructuradas (Valles, 2002). De las 64 entrevistas realizadas en el contexto del proyecto marco antes mencionado, se han explotado para este trabajo las 30 correspondientes a los municipios catalanes: 20 a técnicos responsables de la gestión de la inmigración y 10 a cargos políticos responsables de dicha área.

Como se ha anticipado, la selección de municipios para las entrevistas proviene del análisis territorial realizado a nivel de sección censal. Este análisis permitió identificar todos aquellos municipios en los que existen enclaves residenciales según el lugar de nacimiento de la población. A partir de ellos se estableció una categorización teniendo en cuenta tres criterios: 
Tipo de enclave residencial: se han seleccionado aquellos municipios que contuvieran secciones censales clasificadas como «enclaves» siguiendo el método propuesto por (Poulsen, et al., 2001; Johnston, et al., 2002) y adaptado para el caso español por Sabater, et al., (2013). Los tipos de enclave fueron calculados según criterios de concentración basados en los diferentes grupos, dando como resultado 6 grupos de los cuales sólo tres estaban representados en Cataluña ${ }^{1}$ : (I) Comunidades mayoritarias homogéneas (cuando los nacidos en España representan entre el 80 y el 100\% de los residentes en la sección censal); (II) Comunidades mayoritarias no homogéneas (los nacidos en España representan del 50 al 79\%); y (III) Enclaves plurales (los nacidos en España representan entre el 30 y el $49 \%)^{2}$.

Tamaño del municipio: teniendo en cuenta las transferencias monetarias que reciben por parte de la administración central y excluyendo del análisis a los municipios menores de 1.000 habitantes.

Nivel de segregación: es el resultado de haber evaluado los valores de los índices de disimilitud y aislamiento ${ }^{3}$ (Masey y Denton, 1988) para los distintos agregados continentales (latinoamericanos, europeos occidentales, europeos orientales, africanos y asiáticos).

El Cuadro 1 presenta las 28 categorías resultantes de la combinación de los anteriores criterios, teniendo en cuenta que de las posibles combinaciones sólo en el caso de los «enclaves pluralistas» la adecuación a la realidad permitía ser exhaustivos en

1 Las tres categorías restantes, de las que no existen ejemplos en Cataluña corresponden a: (IV) Enclaves mixtos (los nacidos en España representan menos de un 30\% y ningún grupo representa más del 60\%); (V) Enclaves polarizados (donde un grupo extranjero representa más de un 60\% de la población de la sección censal); y, (VI) Enclaves exclusivos (son enclaves polarizados situados en municipios donde más del 30\% de su población corresponde al mismo grupo extranjero).

2 Para una explicación detallada de esta tipología se puede consultar la página web del GEDEM (gedemced.uab.cat/es) o Galeano et al., 2014.

3 Cuando ninguno de los grupos analizados superaba los 30 puntos en el índice de disimilitud ni los 5 puntos en el índice de aislamiento, el nivel de segregación residencial fue clasificado de «bajo». Si al menos uno de los grupos continentales obtuviera valores entre los 30 y 50 puntos del índice de disimilitud y/o los 5 y 15 puntos del de aislamiento, el nivel de segregación fue clasificado de «medio». Si alguno los 50 puntos en el índice de disimilitud y los 15 puntos en el de asilamiento, el nivel de segregación fue «alto». 
los cruces por tamaño de municipio y nivel de segregación. Para las categorías restantes se ha tenido en cuenta intencionadamente que estuvieran representados diferentes tamaños poblacionales y grupos de origen mayoritario. En el caso de Cataluña, no existían ejemplos de enclaves mixtos, polarizados o exclusivos, por lo que se optó por complementar el discurso de los técnicos con el de cargos políticos en el caso de 10 municipios y habida cuenta de representar diferentes posicionamientos ideológicos.

Cuadro 1

CATEGORÍAS DE LAS ENTREVISTAS

\begin{tabular}{|c|c|c|c|c|}
\hline Cat. & Tipo de enclave & Tamaño del municipio & $\begin{array}{l}\text { Nivel de } \\
\text { segregación }\end{array}$ & N.E. \\
\hline 1 & \multirow{3}{*}{ Mayoritaria homogénea } & $1.000-10.000$ & Baja & \\
\hline 2 & & $30.000-50.000$ & Media & \\
\hline 3 & & $100.000-1.000 .000$ & Media & \\
\hline 4 & \multirow{4}{*}{ Mayoritaria NO homogénea } & $1.000-10.000$ & Baja & \\
\hline 5 & & $30.000-50.000$ & Baja & \\
\hline 6 & & $50.000-100.000$ & Baja & \\
\hline 6 bis & & & & \\
\hline 7 & Pluralista & $1.000-10.000$ & Baja & \\
\hline 8 & Pluralista & $1.000-10.000$ & Media & \\
\hline 9 & \multirow{7}{*}{ Pluralista } & $1.000-10.000$ & Alta & 1 \\
\hline 10 & & \multirow{3}{*}{$10.000-30.000$} & Baja & 2 \\
\hline 11 & & & Media & 2 \\
\hline 12 & & & Alta & 1 \\
\hline 13 & & \multirow{3}{*}{$30.000-50.000$} & Baja & 1 \\
\hline 14 & & & Media & 4 \\
\hline $14 \mathrm{bis}$ & & & Media & 1 \\
\hline 15 & Pluralista & $30.000-50.000$ & Alta & \\
\hline 16 & Pluralista & $50.000-100.000$ & Baja & \\
\hline 17 & Pluralista & $50.000-100.000$ & Media & \\
\hline 18 & Pluralista & $50.000-100.000$ & Alta & \\
\hline 19 & \multirow{6}{*}{ Pluralista } & \multirow{5}{*}{$100.000-1.000 .000$} & Baja & 1 \\
\hline 20 & & & \multirow{2}{*}{ Media } & 6 \\
\hline $20 \mathrm{bis}$ & & & & 1 \\
\hline 21 & & & \multirow{2}{*}{ Alta } & 1 \\
\hline $21 \mathrm{bis}$ & & & & 3 \\
\hline 22 & & $>1.000 .000$ & Baja & 18 \\
\hline 23 & \multirow{2}{*}{ Mixto } & & & \\
\hline 24 & & & & \\
\hline 25 & \multirow{2}{*}{ Polarizado } & & & \\
\hline 26 & & & & \\
\hline 27 & \multirow{2}{*}{ Exclusivo } & & & \\
\hline 28 & & & & \\
\hline
\end{tabular}

Cat.: Categoría; N.E.: Número de enclaves 
Los 20 municipios en los que se realizaron las entrevistas fueron los siguientes: Badalona, Barcelona, Calaf, Castelló d’Empuries, Celrà, Figueres, Guissona, Hospitalet de Llobregat, Lleida, Manresa, Mataró, Montornès del Vallès, Olot, Reus, Rubí, Salou, Salt, Santa Coloma de Gramenet, Tortosa, y Vic.

Tras el trabajo de campo realizado en 2013, el proceso de análisis se puede sintetizar en cuatro pasos principales. En primer lugar, se realizó una doble codificación piloto por parte de ambos autores. Este proceso incluía por una parte la codificación estructural identificando los temas principales: y por otra, la emergencia de códigos mediante el método inductivo. Una vez alcanzado el punto de saturación en la elaboración del listado de códigos, se procedió a una segunda etapa de doble codificación del total de las entrevistas. En tercer lugar, una vez seleccionados los códigos específicos vinculantes para este trabajo, se procedió a la categorización, conceptualización y análisis del contenido de los mismos, así como a la selección de citas representativas. Finalmente se elaboraron los mapas conceptuales que aquí se presentan.

El guión de la entrevista constaba de cuatro bloques temáticos: 1) Sobre la gestión de la inmigración; 2) Sobre la población residente en el municipio y el posicionamiento consistorial; 3) Sobre el impacto de la crisis económica; y 4) Valoración y sugerencias para el futuro. En este trabajo explotamos principalmente los contenidos relativos a los bloques 3 y 4 .

\section{EL DISCURSO NORMATIVO: DE LA DIVERSIDAD A LA INTERCULTURALIDAD}

\subsection{Espacio y tempo interculturales}

La interculturalidad aparece generalmente, aunque no siempre, como el modelo normativo de la gestión de la diversidad cultural, definido por una de las entrevistadas como «proceso de asimilación mutua para la estructuración de una nueva ciudadanía», y que tiene por norte la preservación de la cohesión social. Donde la diversidad en su acepción más simple rinde cuentas del número de nacionalidades llegadas al municipio, y en la más compleja incorpora la pluralidad lingüística asociada, la religiosa o la socioeconómica, 
pero también las condiciones diferentes en las que se produce el proceso migratorio y que marcarán la situación heterogénea en la que se encuentran los inmigrados: condiciones familiares, laborales, de edad en el momento de llegar, de género. Pero, por encima de todo, predomina la percepción del pluralismo cultural (excepcionalmente también definido como étnico para introducir el tema del racismo).

En lo referente a la gestión, ese mismo discurso normativo asocia la diversidad positivamente con la idea de riqueza intercultural, dando cuenta de la categoría ética en la que ha acabado convirtiéndose (Vertovec, 2012), siendo la diversidad originada por las migraciones tan sólo uno de los componentes de la misma, y por tanto de las políticas dirigidas a su gestión (Zapata y Van Ewijk, 2011). Por otra parte, no falta quién señale «el cansancio de la diversidad», en el sentido de subrayar el esfuerzo pedagógico que exige para deshacer los entuertos que prejuicios y malentendidos propios de la diversidad implican. En este espectro encontramos una amplia gama de acciones, desde la simple celebración de la diferencia cultural (muestras de gastronomía, artesanía, indumentarias o festejos folklóricos), hasta la exigencia de ver reflejado en el personal dedicado a la gestión la composición por orígenes del municipio, pasando por el diseño de acciones que fuercen el contacto intercultural (mediación intercultural en general, búsqueda de líderes que sinteticen el paradigma intercultural, negocios étnicos, actividades deportivas conjuntas, refuerzo lingüístico para poder posibilitar la comunicación, creación de espacios ecuménicos para la diversidad religiosa), o de órganos de representación y participación municipales encauzados hacia ese principio (pensados como espacio de debate e intercambio, y definidos como «Foros interculturales» o «Mesas por la convivencia»). Aunque también es frecuente encontrar un cierto grado de frustración por la distancia entre los objetivos perseguidos y la limitación de los resultados, como se expresa repetidamente en el empeño de fomentar la interrelación y el conocimiento mutuo de personas de origen diverso, a veces concretado en términos de convivencia o entendimiento. En este sentido, el trabajo del gestor se orienta tanto al inmigrado como al autóctono, y sin que en ocasiones se sea consciente de ello, la gestión acaba substrayéndose de unos y otros, para reivindicar el arbitraje (cuyo máximo exponente serían las acciones de "sensibilización» dirigidas preferentemente a autóctonos pero también a inmigrados) concibiendo la reciprocidad o bidireccionalidad como un elemento 
clave de la interculturalidad. No obstante, el gestor es también consciente de la necesidad de guiar sus acciones hacia la propia administración local en términos de "capacitación intercultural», así como hacia entidades locales y el mundo asociativo. Esto, se concibe como una herramienta imprescindible en el proceso y utilizada a modo de mediación, que "cree vínculos y estructuras» $\mathrm{y}$ funcione de «elemento integrador» desde una perspectiva global, esto es, encaminada a toda la población.

La dimensión espacial en el discurso de la interculturalidad se plasma en la idea de "proximidad» en el territorio, más allá de la entidad municipal, donde la acción se localiza a menudo en el espacio público, en los barrios o en las comunidades vecinales, pero también en espacios de encuentro e interrelación como locales municipales, asociaciones o bibliotecas. Estudios previos han señalado ya la importancia de estos espacios de encuentro y mediación especialmente en referencia al tejido asociativo (Vecina, 2010) y las bibliotecas municipales (Cervantes y Navas, 2013). Desde una visión aplicada se prioriza la «vida comunitaria» más allá de la "cohesión social» (en sentido amplio) donde el gestor se ve a sí mismo como la figura que debe «fomentar», y en ocasiones incluso "forzar», ese encuentro, esa aproximación o acercamiento entre los vecinos, cuando la experiencia demuestra que ello, no acontece de forma natural. Con todo, generar esos "espacios de encuentro» y que ello se conjugue con una efectiva participación ciudadana, es una tarea expuesta a múltiples dificultades por lo que es percibida siempre como un reto. El técnico además se ve a sí mismo, en contraposición al político como garante de ese espacio de encuentro dada su proximidad diaria con la población inmigrada de la que el perfil político usualmente carece. El trabajo de Dominguez y Brey (2010) pone también este hecho de manifiesto. Por su parte, la dimensión temporal está también muy presente, sentenciando el transcurso de un proceso lento y progresivo, para el que ya no hay vuelta atrás, y cuya meta se visualiza en el reto de la convivencia y la igualdad de oportunidades. Esta «idea de proceso» (poco a poco, ir poniendo granitos, superar los problemas que vayan surgiendo) se acompaña de la consciencia de que es necesario el acompañamiento por parte de la administración en un proceso de re-socialización que se conoce lento, aunque algunos expresan una «sensación de progreso», observado en las realidades cotidianas de sus propias localidades que justifican no en vano el empeño. La percepción 
de dificultad emerge del discurso, en tanto en cuanto, las ideas de «esfuerzo» y «reto» son asiduamente mentadas, habiéndose ésta enardecido en tiempos de recesión económica.

El influjo de la crisis se deja sentir en la introducción del argumento sobre la necesidad de contemplar la igualdad de oportunidades como marco referencial de la convivencia, o simplemente en la imposibilidad de abordar esas acciones cuando el recorte presupuestario ha reducido el margen de actuación a la respuesta simplemente asistencial, sentido esto por el gestor como un infortunio en su quehacer. En los discursos se percibe como el anhelo por la igualdad de oportunidades queda depositado en la infancia, donde las escuelas e institutos son considerados inmejorables espacios de normalización y de prevención en actitudes de racismo y xenofobia.

\subsection{Normativización: identidad y nueva ciudadanía}

¿Por qué discurso normativo? Por un lado la interculturalidad ha sido adoptada en Cataluña como la línea oficial que marca una política de inmigración obligadamente centrada en el asentamiento - ya que el control de flujos es competencia exclusiva del Estado (Zapata, 2012). Presentada habitualmente como «tercera vía» o vía propia, equidistante entre el llamado modelo "asimilacionistas» y el «multicultural». En este sentido resulta paradigmático el caso catalán (Bisrl y Soler, 2004), donde la interculturalidad deviene una definición identitaria haciendo referencia a la tradición inmigratoria del país y al peso que ha ido adquiriendo ese fenómeno demográfico en la propia definición de Cataluña como nación y en la identidad de los catalanes (Domingo, 2014). Esa «tercera vía» que nace de la formulación de una doctrina sobre la inmigración que permita definir la propia identidad, forzada por la experiencia inmigratoria anterior, ha sido modulada bajo el influjo del paradigma de la política migratoria del Quebec, donde la interculturalidad se distanciaría del multiculturalismo, precisamente para enfatizar la identidad nacional propia en el conjunto de Canadá (Zapata, 2008; Reitz, 2012). En el discurso de los entrevistados se manifiesta mediante la cita recurrente a la propia memoria familiar (en su condición de inmigrante o descendiente de inmigrantes procedentes del resto de España durante las migraciones del siglo xx). En este caso, la 
comparación entre las condiciones de los anteriores migrantes y los actuales y de las condiciones que encontraron unos y otros, es constante, jugando un papel crucial en el auto-reconocimiento tanto como en la distancia. Sin embargo, tampoco es infrecuente encontrar que la identidad tenga en el municipio su referente principal, como hemos constatado igualmente en muchas de las entrevistas realizadas en el resto de España. Entonces, la identidad adopta la forma de la propia idiosincrasia del municipio, relacionada con un modelo propio de ciudad, y por tanto de gestión.

En segundo lugar, esa orientación es presentada también de forma canónica cuando en el municipio ha definido la «interculturalidad» como objetivo propio de la gestión de la diversidad, en este caso relacionado con el concepto de nueva ciudanía desarrollado durante los años noventa (Bosniak, 2007), y usualmente asociado con la pertenencia a redes europeas definidas con tal propósito, como por ejemplo la Red Española de Ciudades Interculturales, $\mathrm{RECI}^{4}$, siendo entre los municipios contactados, el caso de Barcelona. A los que se puede añadir, aquellos municipios que han concertado acciones específicas de formación en la gestión intercultural, en los que la persona entrevistada ha participado, especialmente el programa subvencionado por la Obra Social «La Caixa», dirigido por el antropólogo Carlos Giménez, que en el momento de la realización del trabajo de campo se estaba dando en tres de los municipios catalanes cuyos técnicos han sido entrevistados (Giménez, 2012; Giménez y Lobera, 2014): Barcelona, Tortosa, y Salt. El vocabulario y la definición del mismo eran claramente reconocibles, por ejemplo: "coexistencia» diferenciado de «interculturalidad», en el que la primera es expresada popularmente como «vivir de espaldas», y la última definida como el transcurso de la coexistencia a la convivencia. Parte de ese discurso normativo pasa por la práctica de la transversalidad en la gestión municipal global y la superación de los conceptos de «inmigrante» e «integración», no sin expresar el gestor la disconformidad que supone el comprobar la ineficiencia de lo teórico en lo aplicado.

4 La RECI constituye la red nacional del proyecto «Intercultural cities» promovido por el Consejo de Europa. 


\section{CRISIS ¿QUÉ CRISIS?}

\section{1. ¿Cambio de prioridades o superación de una etapa?}

La incertidumbre sobre el calado de la crisis y lo que ésta va a significar en la gestión, es omnipresente en todos los entrevistados. Aunque las medidas tomadas son aparentemente comunes, distinguimos dos niveles en cuanto al grado en que la crisis ha incidido en la gestión, destacando por una parte medidas de reorientación y por otra de transformación. La priorización, el paso a la acción más generalista que afecta al organigrama y la nomenclatura de los servicios municipales, junto con nuevas estrategias para aumentar la eficacia, son algunas. Sin embargo, se discrepa en la interpretación sobre el significado de esas transformaciones y el futuro de las mismas.

En la línea de la reorientación encontramos a los que reivindican la crisis como una oportunidad para modificar la gestión, no falta la vindicación de prácticas ligadas al empadronamiento de mayor rigor o restricción que en el pasado les fueron censuradas. De ese discurso subyace la idea que el mayor control en sentido restrictivo antes no hubiera sido aceptado, y ahora en cambio es promovido.

«Bueno nosotros en el 2008 hicimos el protocolo del Padrón, de arraigo y de reagrupación. Nosotros, como decía, el casco antiguo era un descontrol total, eh!. Por eso se hizo un protocolo...., (..) un protocolo que ahora la Generalitat ya lo hace pero...., fuimos muy criticados porque pedíamos la cédula de habitabilidad, (...) que el contrato estuviera pasado por el registro de la propiedad... Pedíamos lo que pedía la Ley» (30.000-50.000, sin enclaves, segregación media $)^{5}$

La reorientación aparece también en el sentido del cambio de perspectiva. Se hace notar que un servicio más generalista impulsado por el nuevo modelo -tanto sea por los recortes presupuestarios, como por la caída real de los flujos-, puede normalizar lo que desde un principio debería haber sido la perspectiva de la ciudadanía y no la diferencia taxonómica impuesta por la inmigración, adoptada en

5 De no indicarse lo contrario, todas las citas han sido traducidas del original en catalàn por los autores 
el primer momento. Esa tendencia universalista en la acción ha sido apuntada también en trabajos previos (Dominguez y Brey, 2010)

"...en nuestro caso la reflexión que hacíamos, ya la hicimos en el 2007, y quizás entonces era precipitada, era decir: «dejemos de hablar de inmigración y hablemos de ciudadanía».(...)¿Ostras, cómo podemos priorizar los recursos? Pero al mismo tiempo, estamos haciendo una tarea complementaria, y hacemos una cosa nueva. Ya no hablamos de inmigración, hablamos de inclusión social, y obviamente los inmigrantes son un colectivo frágil al que tenemos que tener en cuenta pero igual que a los demás». (30.000-50.000, sin enclaves, segregación baja)

En la línea de la transformación, la crisis puede aparecer como el pretexto para imponer otro modo de gestión, que con anterioridad hubiera sido difícil imponer. Diversos técnicos expresan esa convicción, aunque unos se refieran a la gestión propiamente dicha (con parámetros en nombre de la eficiencia), y otros, al objeto de esa gestión (de la inmigración a la ciudadanía).

"Yo creo que no es una crisis económica, es una crisis social, económica y política y está cambiando la gestión de todo, no sólo de la inmigración, no sé, ;Eh! Lo que pasa es que seguramente con la excusa de la crisis económica se están introduciendo maneras de hacer que hasta ahora no podíamos controlar...» (30.000-50.000, sin enclaves, segregación baja)

De producirse un cambio en el consistorio a raíz de las elecciones municipales de 2012, esa transformación radical puede también presentarse como una ruptura completa y brutal del trabajo realizado anteriormente:

"Hay una dificultad añadida, ¿no? ... en algunos casos incluso el nivel de los gestores políticos que... yo creo que tendrían que hacer algún curso formativo, quiero decir que bueno, no digo ninguna tontería (...) hay otros países que lo hacen y después..., que no hay una hoja de ruta en estos temas... Cada uno va con su idea, y a milo primero que me dijeron los que hay ahora es: "iTodos fuera, los queremos todos fuera! (...) Dije, bueno los vas a tener fuera, de aquí a cuatro años, todos estarán nacionalizados (rie) todos serán españoles». (30.000-50.000, enclave pluralista, segregación media) 
Aunque de hecho nadie formalice el discurso como un cambio de política intencionado y previo, los hay que ven en las modificaciones provocadas por la escasez de recursos una mejora, de acuerdo con el discurso de la "gestión empresarial», detectable en el vocabulario que se utiliza:

"El organigrama ha cambiado radicalmente, las áreas han desaparecido, se han creado otras nuevas, hay técnicas que se han reciclado, no, no te puedes quedar haciendo lo que ya no toca, no te puedes quedar con bolsas de trabajo cuando tienes que idear un sistema de intermediación con la empresa de soporte global, una aula para la búsqueda activa de ocupación (....) ....Ahora hemos abierto una nueva línea de trabajo, hace justo un par de años que hemos cambiado toda la estructura del ayuntamiento, los técnicos, las funciones, que estamos a punto de abrir este Centro de Emprendedores, de hecho los retos son estos ahora, much a formación, mucha alfabetización, mucha emprendeduría, ahora tenemos que seguir esta línea...» (10.000-30.000, enclave pluralista, segregación baja)

La caída de los flujos y el cambio de perfil de la población inmigrada, son los factores demográficos que explican el cambio de gestión. Se ha pasado de plantear necesidades que eran mayoritariamente atendidas mediante acciones de acogida y asesoramiento legal, a aquellas centradas en la inserción laboral (solicitar trabajo, formación ocupacional y de idiomas), residencial (ayudas de alquiler, de hipoteca, o mediación en caso de desahucio), las específicamente dirigidas a los menores (ayudas de guarderías, de comedor escolar, de libros), puntualmente de retorno, y en general para la subsistencia de la economía familiar (rentas mínimas, ayudas de urgencia, de alimentos, de suministros del hogar). El retorno y la re-emigración traen consigo no sólo un retroceso en la llegada de familiares reagrupados, sino también un incremento de la disgregación familiar. Numerosos técnicos, perciben sin embargo con cierto desaliento, la sensación de haber dado un paso atrás, viendo desde la impotencia como los servicios sociales retroceden hacia un asistencialismo que se creía ya superado. 
Mapa conceptual 1

CRISIS, ¿QUÉ CRISIS?

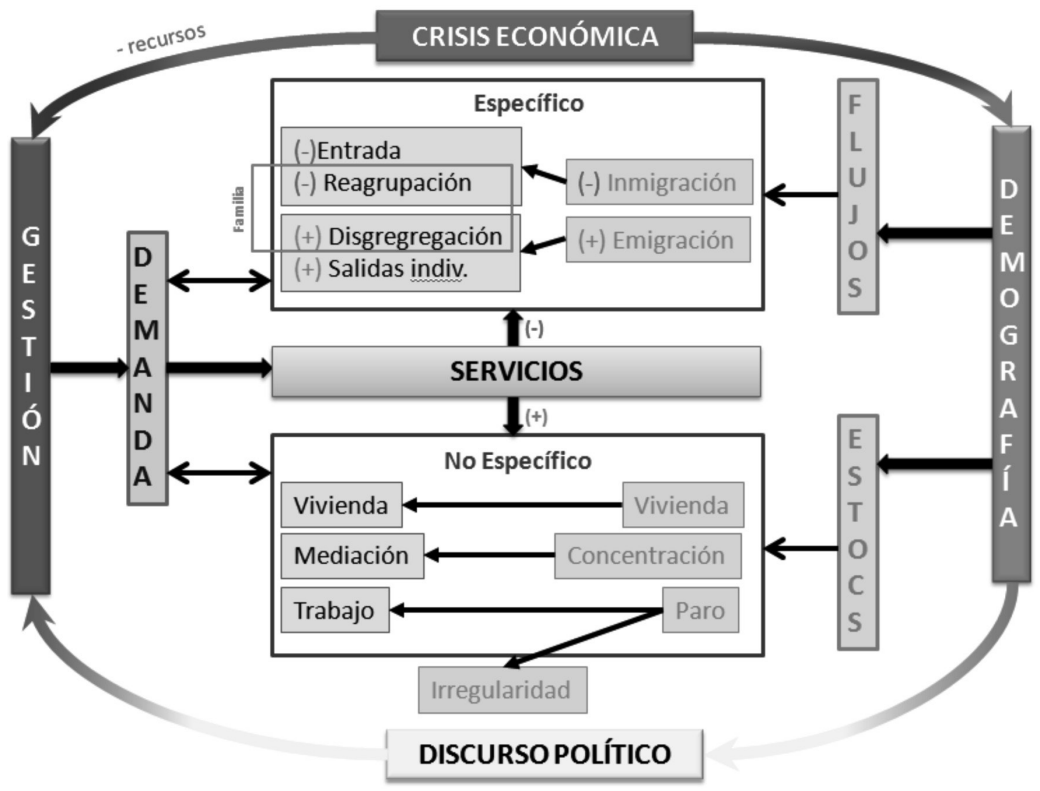

Nos encontramos pues ante efectos diferentes producto del entrecruzamiento de la presión meramente material: la crisis económica, y aquella que nace de una voluntad de replantearse la dirección, a la que llamaremos «crisis de modelo». Si bien la crisis de modelo se suele presentar como producto necesario de adecuación al nuevo contexto material, no necesariamente es así. Dicho de otro modo: la crisis económica se convierte en el pretexto para hacer aceptable el nuevo modelo.

\subsection{Más con menos}

Más allá de la orientación de la gestión, ésta se ha visto progresivamente afectada en lo material. El aspecto más destacado por los entrevistados es la menor disponibilidad de recursos económicos, y no en pocos casos esos recortes han repercutido en una 
reducción en los recursos humanos. En la mejor de las situaciones se han suplido los recortes extra-municipales (Generalitat de Catalunya, Estado, UE) con presupuestos del propio consistorio. Una de las transformaciones más destacadas la constituyen las modificaciones en el organigrama. La inercia parece avanzar hacia la transversalidad, vista por unos como positiva -si se traduce en un trabajo comunitario desde las diferentes áreas municipales- y por otros como negativa -cuando implica una disolución de la atención al migrante sentida aún como necesaria-. Algunos de los cambios mencionados pasan también por la fusión de departamentos, los cambios de nomenclatura o el reciclaje de las funciones del equipo técnico.

"...se ha reducido de una manera dramática, drástica, terrible,... los presupuestos que había dirigidos al área, con lo cual, con lo que te han dejado, te han dicho, gestiona..., esto es lo que hay, gestiona» (30.000-50.000, enclave pluralista, segregación baja)

En términos de capital humano, se ha aplicado la lógica del último en llegar, primero en salir -teniendo en cuenta además la gran variabilidad de tipos contractuales de las personas implicadas en el servicio-, de modo que ha sido la figura del mediador intercultural de la que primero se ha prescindido. Especialmente porque se dio la circunstancia de que muchos de los contratos bajo esta figura, se habían realizado gracias a convenios especiales con entidades privadas que habían asumido la subvención puntual que permitió su contratación pero no la continuidad de los mismos. El primer efecto perverso de la crisis fue expulsar de la gestión a los pocos ciudadanos de origen inmigrado contratados, mayoritariamente mujeres, dando al traste con una de las acciones que la tensión a raíz de la crisis haría más necesaria. Pero también echando por tierra la ejemplaridad que la integración en la administración de personas inmigradas (correspondientes a los mismos colectivos representados en el municipio) tiene tanto para la población autóctona como para la inmigrada.

"Hombre a nosotros nos ha afectado de lleno, de lleno, y bueno, no somos ni mucho menos los únicos..., mucha gente..., nosotros claro, sufrimos los recortes primero de todo de las mediadoras» (1.000-10.000, sin enclaves, segregación baja) 
El técnico por otra parte, se reafirma en la responsabilidad que su servicio tiene para con la población inmigrada y en el esfuerzo que en todo caso ha supuesto mantener unas políticas y unos servicios básicos de atención primaria con cada vez menos recursos. He aquí donde encontramos cómo parte la gestión en tiempos de crisis recae en la voluntad del propio técnico por hallar recursos alternativos o estibar los ya disponibles, elaborando una economía de escala ad hoc en cada caso. La captación de nuevos recursos pasa a ser entonces, una condición sine qua non para la continuidad del servicio (no la necesidad del mismo).

Sin embargo, como ya anticipábamos, el alcance de la crisis no ha sido homogéneo. Son aquellos municipios de mayor tamaño -y mayor presupuesto- o aquellos caracterizados por dedicarse a las actividades que mejor han resistido a la crisis (industria de transformación agroalimentaria, y turismo, principalmente)-donde apenas hay desempleo- para quienes las condiciones materiales no suponen un impedimento para la gestión. No obstante, no por ello están exentos de padecer los perjuicios colaterales devenidos de la crisis, ya sean en forma de recortes en competencias no transferidas (educación, sanidad) o bien por la propia situación de vulnerabilidad que atraviesa la población inmigrada.

"Nosotros, el Ayuntamiento (...) tiene unas finanzas muy sólidas y hemos mantenido el presupuesto a lo largo de todos estos años de crisis, es más, lo hemos incrementado, que el año pasado incluso incrementamos el presupuesto un poco, ¿no? Así que las políticas las mantenemos y en general también otras áreas del Ayuntamiento las mantienen» (>100.000, enclave pluralista, segregación baja)

\section{EL MIEDO AL DISTURBIO}

Lo intangible del desasosiego provocado por la crisis, mantiene en vilo el futuro de la gestión ante lo impredecible de la recesión de la cual el gestor no atisba indicios de recuperación. Esa inseguridad, se alimenta de dos fuentes. De una parte, por el desconcierto que supone en el gestor el observar el paulatino desmantelamiento de la gestión específica, que muchos de ellos vieron crecer de la nada en tiempo record, acompañada en ocasiones de la mayor o menor abundancia de recursos propios del momento de expansión que vivía 
el país, y generalmente de una gran dosis de voluntarismo. De otra, por el temor a lo peor, al estallido social, dado que afirman observar como se ha generado un caldo de cultivo que aglutina las condiciones necesarias para desembocar en conflictos mayores, que, por otra parte, de alguna manera se enorgullecen de haber evitado gracias a acciones de prevención e intervención comunitaria. Se trata pues, de una posibilidad latente que se percibe como temida. Estudios de opinión recientes han concluido que no existe en España un racismo elevado, aunque sí sutil (D’Ancona, Valles, y Eseverri, 2014). En este sentido, se alude con frecuencia a los disturbios acontecidos en otros países europeos, lo que podríamos llamar «miedo a la banlieue», y al incremento de la xenofobia, tomando Francia como ejemplo (el lepenismo). El nuevo espacio público urbano es a menudo visto como el escenario donde el conflicto permanece latente (Varela, 2008) y la presencia del inmigrante, como actor desconocido, genera recelo entre los anteriores usuarios de ese espacio (Delgado, 2004, 2009). Inevitablemente esa referencia, y ese temor, se hace más presente en los municipios donde se han implantado formaciones políticas de carácter xenófobo, como Plataforma por Cataluña. Porque la espada de Damocles del desorden social, es percibida como el resultado de la explotación populista del conflicto que puede darse por la competencia entre autóctonos e inmigrados por unos recursos cada vez más escasos que por un estallido de la población excluida de origen inmigrado.

Por lo general, no obstante, el gestor niega la existencia de conflicto como tal, aunque ninguno de ellos esconde (salvo excepciones) la existencia de fricciones entre la población y ciertos problemas de convivencia, amplificados en tiempos de recesión económica. El aumento generalizado de la pobreza, es una valoración compartida por los técnicos. Sin embargo, se considera a la población inmigrada el colectivo más vulnerable a las vicisitudes de la crisis dado que cuenta con una red de apoyo social y familiar menor que la de la autóctona (compensada a veces, según los entrevistados, por una mayor solidaridad tanto interfamiliar como de la comunidad de origen). El hecho de que los autóctonos hayan visto aumentar también sus niveles de privación material, da como resultado una situación de competencia por los recursos entre inmigrados y no inmigrados. De hecho, de cómo en época de crisis la actitud de la población autóctona evolucionó hacia el discurso del resentimiento y de la preferencia, en representación del racismo simbólico (Kinders 


\section{Mapa conceptual 2}

\section{CONFLICTO}

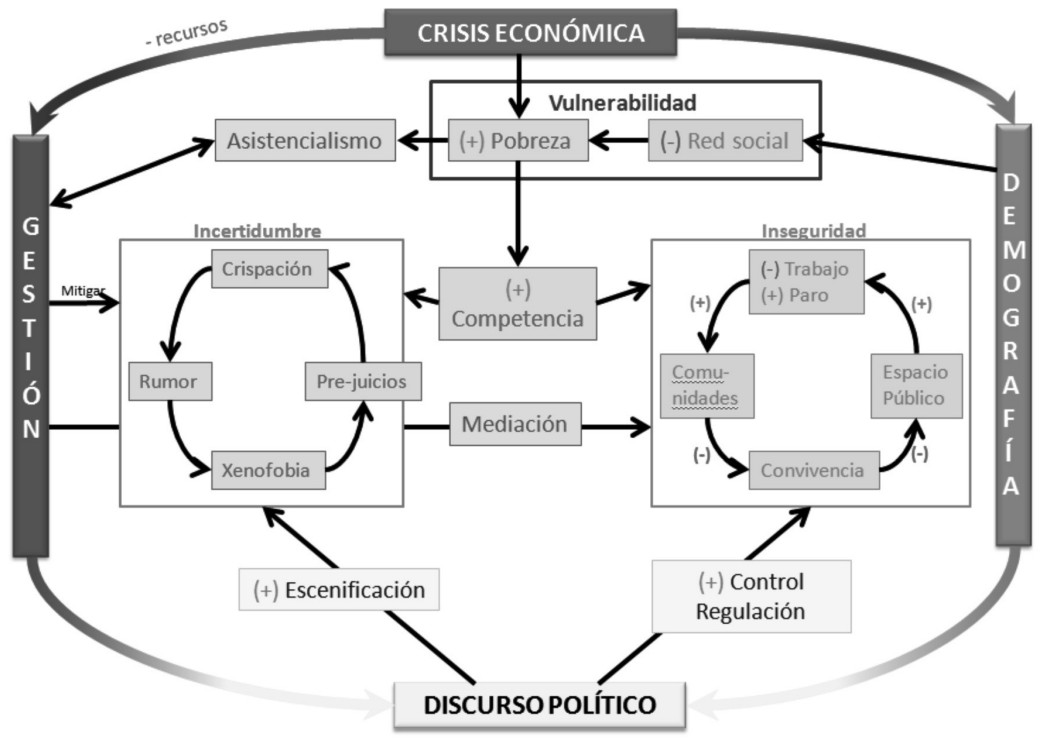

y Sears, 1981), se hicieron eco diversos trabajos (Cea d'Ancona y Valles, 2010, 2013). De lo transmitido por los entrevistados, podemos afirmar que esa tensión generada se retroalimenta de dos procesos. En primer lugar, el que hemos venido a llamar el círculo de la inseguridad, por el cual el gestor ha observado que el mayor desempleo (en especial masculino), ha desencadenado una mayor presencia en el espacio público, pero también en los hogares y comunidades vecinales, lo que a su vez desemboca en problemas de convivencia e incremento de las tensiones. En segundo lugar, la percepción de inseguridad nutre al mismo tiempo el que hemos calificado de círculo de la incertidumbre basado en cómo el técnico ve convertirse la competencia en crispación, basada en la difusión de prejuicios y rumores de carácter xenófobo y racista. Es objetivo del gestor pues, pasa a luchar por mitigar los efectos de ese círculo vicioso, pero más importante si cabe resulta actuar sobre su origen, 
que se encuentra en los problemas de convivencia, mediante la mediación comunitaria.

"Sí, hay más malestar a nivel general, este programa que te decía de mediación una de las cosas que hay es que nos parece que la gente está más encrespada..., la gente enseguida se tira los platos a la cabeza, en general eh!, sea gente originaria de aquí, gente..., población de fuera, pero hay más malestar en este sentido..., ¿no?» (50.000-100.000, sin enclaves, segregación baja)

Por otra parte, la percepción obtenida sobre el discurso político, entendiendo éste como el discurso normativo adoptado por la administración y puesto en boca del técnico, nos lleva a concluir que en relación a los problemas de convivencia se ha ejercido, con mayor o menor empeño según el municipio, un mayor control del espacio público y comunitario regulado en forma de ordenanzas de civismo. En algunos casos, dichas ordenanzas, dirigidas a priori a la población residente sin distinción de origen, tenían un claro enfoque hacia regular los comportamientos de la población inmigrada aludiendo a cuestiones relacionadas con horarios, ruido, olores, suciedad, sobreocupación, etc. de forma más o menos evidente. Entre los entrevistados encontramos opiniones divergentes entre quienes se posicionan a favor de este tipo de medidas para solucionar las fricciones de la convivencia.

«...para solucionar este tipo de problemas incluso tenemos un tríptico en todos los idiomas posibles..., musulmán, árabe, para que la gente se dé cuenta de lo que puede y no puede hacer, una crucecita de lo que no puedes hacer, dibujos, una casa, uno timbrando a las doce de la noche..., evidentemente no se puede, en fin un poco didáctico como casi si fuesen niños, y hemos evitado muchísimos, muchísimos problemas de verdad...» (10.000-30.000, enclave pluralista, segregación media. Político) [cita original]

Y quienes, por el contrario, adoptan una actitud crítica entendiéndolo como una medida asimilacionista que evita abordar el reto de la diversidad poblacional.

"El otro caballo de batalla es el civismo, el civismo esconde todas las cosas, es decir, todos los problemas de origen socioeconómico ahora les llamamos civismo, es muy..., (...) el tema del civismo ha servido durante años para tratar el tema de la diversidad, como 
no podemos hablar ni de inmigrantes, ni podemos hablar de no sé qué, ni de no sé cuantos, hablamos de civismo y así arreglamos los problemas (...) es muy normalizador» (50.000-100.000, sin enclaves, segregación baja)

Por último, es importante señalar que si la gestión de la inmigración siempre ha sido acompañada, también a nivel municipal, por cierta puesta en escena, que en épocas anteriores fue dominada por el lema de "poner orden», a partir de la crisis, según algunos de los entrevistados reclama una escenificación basada en el rebajar su visibilidad, para evitar fomentar los rumores de favoritismo hacia la población inmigrada. De esa «invisibilidad relativa» hablan también Domínguez y Brey (2010) en su trabajo sobre San Fernando de Henares (Madrid). Esa concepción, no sólo reforzará el convencimiento de favorecer las acciones generalistas sobre las específicamente dirigidas hacia la población inmigrada, sino de rebajar el perfil de estas últimas, o incluso de las primeras cuando los beneficiados son inmigrados. Esa escenificación ha sido resumida por uno de los entrevistados con la expresión popular catalana: "Aquest és un mal (la atención a la población inmigrada), que no vol soroll» (30.000-50.000, sin enclaves, segregación media), Traducción literal: «Este es un problema que no quiere ruido».

"¿Cuales son los retos de futuro? Yo creo que los objetivos que nos planteamos siguen siendo muy válidos porqué aún no los hemos alcanzado, de hecho la evaluación de los grupos municipales, de los partidos politicos fue muy negativa, en cuanto planteé: La cohesión social, ¿la hemos conseguido? No, pues..., con el pleno no lo hemos conseguido..., en mi pueblo decimos "un mal que no quiere ruido», es decir es una labor que tenemos que hacer con el día a día, que la tenemos que dimensionar correctamente, que la hemos de focalizar, no puede diluirse, tiene que ser una prioridad... (100.000-1.000.000, enclave pluralista, segregación media)

\section{CONCLUSIONES: RIESGO, SEGURIDAD Y OPACIDAD}

Pronunciarse sobre la gestión en tiempos de crisis conlleva inevitablemente hacer referencia a los cambios experimentados por el propio fenómeno demográfico, principalmente la caída de 
los flujos de entrada y el progresivo aumento de los de salida, con sus problemáticas específicas asociadas. Precisamente esa caída de la inmigración explica que el servicio se acabe focalizando casi exclusivamente en las demandas generadas por el asentamiento, eso sí, en condiciones extraordinariamente más precarias que las que se dieron en la época de crecimiento. Cuanto más necesarios eran los recursos humanos y materiales dirigidos a la misma es cuando menos se le va a destinar. El aumento de la vulnerabilidad, en términos de población, y de la guetización, en términos de territorio, van a sintetizar un miedo que se proyecta fundamentalmente al futuro, bajo el epígrafe de "cohesión social» y que se traduce en diferentes medidas de transformación y orientación de la gestión local.

La transformación de las condiciones materiales, se resumen en el paso de la gestión de una relativa abundancia (ni tanta ni para todos) a una relativa escasez (como hemos visto, la incidencia del recorte presupuestario asumido no ha sido igual para todos los municipios). Aunque esa escasez, hay que decirlo, se ha debido también a la jerarquización de las prioridades que se han dado en cada consistorio. Esas mutaciones pues, tanto en el propio fenómeno como en los medios disponibles, han implicado cambios en el modelo de gestión. No hay que subestimar tampoco las varianzas institucionales a raíz del resultado de las diferentes elecciones, empezando por las autonómicas (2010), municipales (2011) y del conjunto del Estado (2012) que tendrán claras repercusiones en el abordaje de la política local de la interculturalidad. Esas transformaciones, han sido interpretadas por los entrevistados de tres formas diferentes, aunque no excluyentes: 1) aquellos que han visto el momento de vindicar su gestión anterior, criticada por su excesivo celo o rigor; 2) los que han aprovechado la coyuntura o se han adaptado a ella mediante ajustes en la organización y la priorización de los servicios prestados; y 3) aquellos que siguen pensando en todo lo que la crisis ha truncado. Aparentemente todos se han movido en una misma dirección, sin que en el discurso se deje notar que ese viraje haya sido impuesto directamente por otros niveles administrativos superiores. El cambio de modelo, sin embargo, incluye posiciones encontradas, desde los entrevistados para los que el ajuste está en sintonía con el discurso sobre la austeridad imperante, que aproximan su concepción de la eficiencia a la gestión empresarial, perspectiva iniciada con anterioridad a la crisis (flexibilización contractual, externalización de actividades, 
supeditación de las acciones a la captación de recursos externos), y generalmente decidida en el ámbito político (no en el técnico), y aquellos que ven en la necesidad de racionalización de los medios una oportunidad para replantear de forma más radical qué significa el servicio público a una nueva parte de la vecindad del municipio (a la que ya no debería llamarse inmigrados). Con todo, los técnicos consideran que el discurso institucional de la interculturalidad, aún interiorizándolo como «el camino a seguir», en pocas ocasiones se adecua a la realidad vivida en los municipios, adquiriendo incluso un carácter cuasi utópico aún muy lejos de ser alcanzable.

La incertidumbre causada por la crisis económica, tiene como primera consecuencia que el discurso de los técnicos de inmigración se enuncie en forma de riesgo. Ya no se trata tanto de conseguir el ideal de una sociedad intercultural - aunque este objetivo normativo no se ponga en duda-, como de evitar el conflicto, la amenaza de fractura de la cohesión social (entendida como la relación armónica o integrada en el futuro). Es por ello que el discurso sobre la seguridad por un lado, y el de arbitraje -o mediación-, por otro, crecen o toman un protagonismo que en la etapa anterior no tenían, a juzgar por el relato que los propios entrevistados realizan sobre la génesis del área de inmigración. El pesimismo generado por la incertidumbre de larga duración hace que algunos asuman los límites de la interculturalidad como un imponderable: si no es por la dificultad intrínseca de mantener y crear espacios de interrelación entre los diferentes grupos poblacionales, lo es por el encapsulamiento y la segregación que la propia crisis económica acelera, ejemplificado en la preocupación por el empeoramiento de la convivencia en el espacio público; en la apuesta por la mediación intercultural de un lado -eso sí, truncada por la crisis- y la imposición normativa de decálogos del civismo por otro. El objetivo último de esas acciones sería mitigar la crispación y las incipientes muestras xenófobas que produce el progresivo deterioro de las condiciones de vida de los vecinos, sean autóctonos o inmigrados. A todo ello al técnico se le exigen en ocasiones conocimientos de prestidigitación para convertir en invisibles su acciones sin que dejen de realizarse. La presión que significan los grupos xenófobos organizados se deja sentir, al procurar la opacidad de las propias acciones, cuando estas pueden ser específicamente dirigidas a la población inmigrada, o en demostrar a la población autóctona que los recursos se distribuyen equitativamente. 
La mayoría de entrevistados, acaban poniendo en evidencia el ilusionismo de un discurso que constantemente apela al voluntarismo del técnico para sostener un servicio marcado por la creciente precariedad.

\section{AGRADECIMIENTOS}

Los autores queremos hacer constar nuestro profundo agradecimiento a todos los técnicos y cargos políticos responsables de la gestión de la inmigración en el ámbito local que colaboraron con este proyecto dedicándonos su tiempo e implicación.

Este trabajo fue realizado en el marco de las investigaciones «Diversidad, segregación y vulnerabilidad: análisis sociodemográfico» financiada por el Plan Nacional de I+D+I 2014 (Ref. CSO201453413-R) e «Immigrant population settlement, demographic change and local management of interculturality» financiada por la Obra Social La Caixa y la Associació Catalana d'Universitats Públiques (ACUP), bajo la convocatoria Recercaixa 2011.

\section{REFERENCIAS BIBLIOGRÁFICAS}

Bisrl, U. y SolÉ, C. (Coords) (2004): Migración e interculturalidad en Gran Bretaña, España y Alemania. Barcelona, Anthropos.

Boletín Oficial del Estado (2013): Ley 27/2013, de 27 de diciembre, de racionalización y sostenibilidad de la Administración Local. BOE, número 312 del Lunes 30 de Diciembre de 2013, Sección 1, Página 106430, Congreso de los Diputados.

BosnIAK, L. (2007): «Being Here: Ethical Territoriality and the Rights of Immigrants», Theoretical Inquiries in Law, Vol. 8, Núm. 1, pp. 389-410.

Cea D’Ancona, Ma Á. y Valles Martínez, M. S. (2010): Xenofobias y xenofilias en clave biográfica. Madrid, Siglo XXI.

Cea D'Ancona, Ma Á. y Valles Martínez, M. S. (2013): Evolución del racismo y la xenofobia en España [Informe 2013]. Madrid, OBERAXE. Ministerio de Trabajo e Inmigración.

Cea D’Ancona, Ma Á., Miguel S. Valles Martínez, y Cecilia Eseverri Mayer. (2014): «Convergencias y divergencias de los discursos e imágenes de la inmigración en etapas de bonanza y de crisis.» Migraciones. Publicación del Instituto Universitario de Estudios sobre Migraciones 0 (35), pp. 9-39. 
Cervantes, L. y Navas, M. (2013): «Las bibliotecas públicas como instrumento para la integración social: un estudio de caso», Migraciones, núm 34, pp. 177-203.

Delgado, M. (2004): «Cultura e inmigración. El espacio público como marco de integración». En J. Rodríguez Roca y J. M. Alonso Varea (Coord.): Repensar la intervención social: los escenarios actuales y futuros. Barcelona, Col-legi Oficial de Psicòlegs de Catalunya.

Delgado, M. (2009): «Seres de otro mundo: sobre la función simbólica del inmigrante». En Mellado, Ll. (coord.): La dinámica del contacto: movilidad, encuentro y conflicto en las relaciones interculturales, CIDOB Ediciones, Barcelona, pp. 13-22.

Domingo, A. (2014): Catalunya al mirall de la immigració. Demografia i identitat nacional. Barcelona, L'Avenç.

Domingo, A.; LóPez-FAlcón, D.; y Bayona, J. (2010): «El reagrupament familiar l'any 2008 a la Província de Barcelona». Alcalde, Rosalina; Bayona, Jordi; Domingo, Andreu; González-Ferrer, Amparo; y López-Falcón, Diana. El reagrupament familiar a Catalunya, una aproximació quantitativa. Barcelona, Fundació Jaume Bofill. Col·lecció Informes Breus, 23, pp. 65-92.

Domingo, A. y SABAter, A. (2010): «El empadronamiento de la población extranjera en los municipios catalanes de 2004 a 2008». Scriptanova, Vol. XIV, núm, p. 344.

Domínguez, M,, y BRey, E. (2010): «Los retos de la inmigración en España: Análisis comparativo de los discursos de la administración y la población inmigrante», Revista del Ministerio de Trabajo e Inmigración, Serie Migraciones Internacionales, 85, pp. 65-79.

DueÑas I Cid, D. (2011): «Jóvenes de Origen Extranjero Y Participación Social. ¿Diferentes Procesos Migratorios Conducen a Diferentes Modelos de Participación?» Revista Internacional de Organizaciones 0 (6), pp. 81-107. doi:10.17345/rio6.81-107.

Galeano, J., Sabater, A., y Domingo, A. (2014): «Formació i evolució dels enclavaments ètnics a Catalunya, abans i durant la crisi econòmica». Documents d'Anàlisi Geogràfica, núm. vol. 60 (2), pp. 1-28.

Generalitat de Catalunya (2009): Pacte per viure junts i juntes. Pacte nacional per a la immigració. Barcelona, Departament d'Acció Social de Ciutadania, Secretaria per a la Immigració, Generalitat de Catalunya.

Gil Araujo, S. (2010): Las argucias de la integración. Políticas migratorias, construcción nacional y cuestión social. Madrid, IEPALA.

GIL CAlvo, E. (2009): Crisis crónica. Madrid, Alianza Editorial, pp. 364-398.

Giménez, C. (2012): Convivencia social e intercultural en territorios de alta diversidad. Encuesta 2010 sobre convivencia intercultural en el ámbito local. Primer informe. Barcelona, Obra Social «la Caixa».

GIMÉNEZ, C. y LOBERA, J. (2014): Convivencia social e interculturalidad en territorios de alta diversidad. Encuesta 2012 sobre convivencia intercultural en el ámbito local. Segundo informe. Barcelona, Obra Social «la Caixa». 
Johnston, R., Forrest, J. y Poulsen, M. (2002): «Are there Etnic Enclaves/ Guettos in English Cities?». Urban Studies, Vol. 39, $n^{\circ} 4$, pp. 591-618.

Kinder, D. R., y D. O. Sears. (1981): «Prejudice and Politics: Symbolic Racism versus Racial Threats to the Good Life.» Journal of Personality and Social Psychology 40 (3), pp. 414-31. doi:10.1037/0022-3514.40.3.414.

Massey, D. S., y Denton, N. A. (1988): «The dimensions of residential segregation». Social forces, 67 (2), pp. 281-315.

Montilla, J. A. y Rodríguez, J. L. (2014): «Las normas generales del Estado sobre inmigración en 2013». En Arango, J.; Moya Malapeira, D. y Oliver Alonso, J. (dir.): Anuario de la inmigración en España (edición 2014): Inmigración y emigración: mitos y realidades. CIDOB. 320.

Poulsen, M.; Johnston, R. y Forrest, J. (2001): «Intraurban ethnic enclaves: introducing a knowledge-based classification method», Environment and Planning, 33, pp. 2071-2082.

Reitz, J. G. (2012): «Managing Immigrants and Diversity in Canada and Quebec: Lessons for Spain?». A RodríGuez-García, D. (Ed.) Managing Immigration and Divesity in Canada. Montreal \& Kingston, McGill-Queen's University Press, pp. 61-84.

Sabater, A., Galeano, J. y Domingo, A. (2013): «La transformación de comunidades mayoritarias y evolución de los enclaves étnicos residenciales en España». Migraciones, 34, pp. 11-44.

SÁnchez, C., SAmper, S. y Moreno, R. (2008): «Dades per a la inscripción al padró municipal», La gestió municipal de l'empadronament dels immigrants. Barcelona, Síndic de Greuges.

Valles, M. S. (2002): Entrevistas cualitativas. Cuadernos Metodológicos, n³2. 195 págs. Centro de Investigaciones Sociológicas, CIS, Madrid.

VALERA, S (2008): "Conflicto y miedo ante un nuevo espacio público urbano». En Fernández-Ramirez, B. y Vidal, T. (eds.) Psicología de la Ciudad. Debate sobre el espacio urbano. Barcelona, Editorial UOC.

Vecina, C. (2010): «Tejido asociativo, convivencia intercultural y desarrollo comunitario». Migraciones, núm. 28, pp. 227-243.

Vertovec, S. (2012): «Diversity and Social Imagery». European Journal of Sociology, 53, pp. 287-312.

ZAPATA-BARRERo, R. (2008) La immigración en naciones minoritarias. Flandes, Quebec y Cataluña en perspectiva. Barcelona, Icaria.

Zapata-BARrero, R. (2012): Una ètica política mínima de la immigració a Catalunya. Barcelona, Proteus.

Zapata-BARRERo, R. y VAN EWIJK, A. R. (eds) (2011): Spheres of diversities: from concept to policy. Barcelona, Fundació CIDOB. 
